\title{
Educación Superior en tiempos de COVID-19: oportunidades y retos de la educación a distancia
}

\author{
Higher Education in times of COVID-19: opportunities and challenges \\ of distance education
}

\section{Educação superior na época da COVID-19: Oportunidades e desafios da educação à distância}

\author{
Ana Cristina Umaña-Mata \\ Universidad Estatal a Distancia \\ San José, Costa Rica \\ acuanam@uned.ac.cr \\ (D) https://orcid.org/0000-0002-7998-1061
}

Recibido - Received - Recebido: 30 / 07 / 2020 Corregido-Revised - Revisado: 03 / 09 / 2020 Aceptado - Accepted - Aprovado: 07 / 09 / 2020

DOI: https://doi.org/10.22458/ie.v22iespecial.3199

URL: https://revistas.uned.ac.cr/index.php/innovaciones/article/view/3199

\begin{abstract}
Resumen: El objetivo de este ensayo es la presentación general de algunas de las principales oportunidades y retos del modelo educativo a distancia como una de las alternativas educativas con mayores posibilidades de desarrollo a nivel latinoamericano, ante las consecuencias evidenciadas en este campo, producto del virus responsable de la COVID-19. En ese sentido, interesa dejar claridad de la conceptualización de dicho modelo educativo y de las particularides a considerar para su diseño y gestión, como una opción viable y de resultados positivos importantes por su trayectoria y, de esta manera, hacer frente a lo que se ha denominado "nueva normalidad". Para tal efecto, se seleccionan las cinco principales situaciones que han impactado el campo educativo: a) la interrupción del periodo académico; b) la abrupta utilización de las tecnologías para el desarrollo de los procesos de enseñanza y aprendizaje; c) la carencia de planificación educativa para el desarrollo de propuestas educativas a distancia con apoyo de tecnologías; d) la falta de recursos didácticos para utilizar en el modelo de educación a distancia; y e) la necesidad de fortalecer el desarrollo de competencias tecnológicas en el personal docente. Entre las oportunidades de la educación a distancia está su filosofía como tal, al igual que los principios metodológicos y evaluativos del modelo. Por otra parte, se destacan retos como el fortalecimiento de la oferta académica y el establecimiento de estrategias de cooperación internacional.
\end{abstract}

Palabras clave: educación superior, educación a distancia, aprendizaje en línea, enseñanza, aprendizaje, COVID-19

\begin{abstract}
The objective of this essay is the general presentation of some of the main opportunities and challenges of the distance education model, as one of the education alternatives with the greatest potential for development in Latin America, given the consequences evidenced in this field, resulting from the virus responsible for COVID-19. In this sense, the purpose is to clarify the conceptualization of said educational model and the particularities to be considered for its design and management, as a viable option and with significant positive results due to its trajectory, to face what has been called the "new normal." To that end, the five main situations that have impacted the educational field are selected: $a$ ) the interruption of the academic period; b) the abrupt use of technologies for the development of teaching and learning processes; c) the lack of educational planning for the development of distance educational proposals with the support of technologies; d) the lack of didactic resources to use in the distance education model; e) the need to strengthen the development of technological competence in teaching staff.
\end{abstract}


Among the opportunities of distance education is its philosophy as such, as well as the methodological and assessment principles of the model. On the other hand, challenges such as strengthening the academic offer and the establishment of international cooperation strategies stand out.

Key Words: higher education, distance education, online learning, teaching, learning, COVID-19

Resumo: $O$ objetivo deste ensaio é a apresentação geral de algumas das principais oportunidades e desafios do modelo de educação à distância, como uma das alternativas educacionais com maiores possibilidades de desenvolvimento em nível latino-americano, tendo em vista as consequências evidenciadas neste campo, produto do vírus responsável pela COVID-19. Neste sentido, é importante esclarecer a conceituação deste modelo educacional e os detalhes a serem considerados para sua concepção e gestão, como uma opção viável com importantes resultados positivos para sua trajetória, para enfrentar o que tem sido chamado de "nova normalidade".

Para este fim, são selecionadas as cinco principais situações que impactaram o campo educacional: a) a interrupção do período acadêmico; b) o uso abrupto de tecnologias para o desenvolvimento de processos de ensino e aprendizagem; c) a falta de planejamento educacional para o desenvolvimento de propostas de educação à distância com o apoio de tecnologias; d) a falta de recursos didáticos a serem utilizados no modelo de educação à distância; e) a necessidade de fortalecer o desenvolvimento da competência tecnológica dos professores.

Entre as oportunidades de educação à distância está sua filosofia como tal, assim como os princípios metodológicos e avaliativos do modelo. Por outro lado, desafios como o fortalecimento da oferta acadêmica e o estabelecimento de estratégias de cooperação internacional são destacados.

Palavras-chave: educação superior, educação à distância, aprendizagem on-line, ensino, aprendizagem, COVID-19

\section{INTRODUCCIÓN}

A finales del mes de diciembre del año 2019, desde Wuhan, provincia de Hubei- China, se inicia el reporte de un brote de contagio masivo de personas con neumonía. En ese momento, la información era preocupante (Seow, 2020); sin embargo, no se tenía certeza de las consecuencias a nivel socioeconómico, de salud y educación a nivel mundial por la pandemia que fue generada ante la propagación del virus que se ha denominado COVID-19.

Las condiciones de contagio del virus, pero, más aún, las afectaciones tan serias a la salud física de las personas, rápidamente llevaron a los gobiernos a tomar medidas que intentaron detener la propagación del virus responsable de la COVID-19, entre las cuales el distanciamento social fue una de adoptadas en todo el mundo (Elgueta, 2020). Esta disposición sanitaria ha traído consigo aspectos reguladores para evitar que se sumaran mayores pérdidas humanas. Aunado a lo anterior, se empezó a tener consecuencias en diversos ámbitos del desarrollo social de los países, en donde se ha visto una caída de las economías, aumentos en el desempleo, así como cambios radicales y acelerados en las normas de convivencia e interacción entre las personas, como producto del aislamiento y el confinamiento en los hogares (Brown y Salmi, 2020).

En el campo educativo y, propiamente en la educación superior, las afectaciones económicas han tenido sus consecuencias importantes. En primer lugar, se puede ver las repercusiones para el personal docente, según lo refiere el informe de IESALC-UNESCO (2020), en el cual se mencione que el profesorado:

Sufre también importantes afectaciones en lo laboral y en lo profesional. En primer lugar, hay que tomar en cuenta que no todas las IES tienen estrategias de continuidad de la actividad docente y, en su ausencia, los contratos temporales pueden quedar rescindidos. Por otra parte, el impacto más evidente sobre el equipo docente está siendo la expectativa, cuando no existe exigencia, de la continuidad de la actividad docente bajo la modalidad virtual (p. 20). 
En este nuevo marco de convivencia, de nuevas reglas, de cambios de rutinas en el hogar y del modelo en que funcionan las instituciones de educación, se ha denominado "nueva normalidad", dado que no es un tema pasajero y que, a pesar de la esperanza que se alberga por el descubrimiento de la vacuna, es inevitable un viraje en los estilos de interacción, las condiciones laborales, el desarrollo del comercio y, por supuesto, la implementación de los modelos educativos. La afectación se verá más marcada en aquellos centros e instituciones de orientación presencial, los cuales ya han sufrido por la suspensión de las lecciones en todos los niveles de educación y la rápida, y hasta violenta, incursión en el uso de recursos tecnológicos para no detener del todo el proceso educativo (Ordorika 2020).

Evidentemente, el traslado de un modelo educativo cuya filosofía sustentan su desarrollo bajo la forma presencial, donde prevalece el contacto "cara a cara" entre el personal docente, el estudiantado y las interacciones se llevan a cabo en un espacio físico denominado "aula", hacia un modelo de educación a distancia, sin que medie una reflexión y el replanteamiento epistemológico del modelo, lleva consigo una serie de limitaciones para su implementación. Sin embargo, bajo las circunstancias del contexto mundial que se viven por la pandemia, se entiende que, a corto plazo, esos esfuerzos se realizan para "aplacar" el fuerte golpe ante la suspensión de la educación (Alcántara, 2020).

A pesar de que el contexto pareciera ser poco alentador, a nivel educativo se cuenta con el modelo de educación a distancia de gran trayectoria y reconocidos éxitos. Las instituciones bajo esta modalidad educativa son las que menos afectaciones han percibido en la población estudiantil y docente. Los recursos tecnológicos con que cuentan y los procesos de capacitación de su personal docente, lo mismo que la experiencia acumulada por años, han permitido que se le reconozca como la mejor opción para que no se dé un estancamiento en la formación de las personas sin que se expongan a situaciones de riesgo (UNESCO/ IESALC, 2020; Crawford, Butler-Henderson, Malkawi; Lam; Rudolph; Magni \& Glowatz, 2020).

Según Crawford et al. (2020), las condiciones favorables de las prácticas de los modelos no presenciales han llevado a las instituciones de educación superior a retomar prácticas virtuales para poder hacer frente al compromiso formativo del estudiantado. Sin embargo, ha sido un proceso acelerado, poco reflexivo y debe verse como emergente. Por lo tanto, sino se realiza una evaluación de las acciones implementadas, como de los factores que por la emergencia no se consideraron, se corre riesgo de generar acciones educativas "activistas" que prontamente perderán vigencia y sostenibilidad.

El objetivo de este ensayo es la presentación general de algunas de las principales oportunidades y retos del modelo educativo a distancia, como una de las alternativas educativas con mayores posibilidades de desarrollo ante las consecuencias evidenciadas en este campo, producto del virus de la COVID-19. En ese sentido, interesa dejar claridad de la conceptualización de dicho modelo educativo y, de las particularides a considerar para su diseño y gestión, como una alternativa viable y de resultados positivos importantes por su trayecto para hacer frente a lo que se ha denominado "nueva normalidad".

\section{DESARROLLO DEL TEMA}

La propagación del virus responsable de la COVID-19 ha generado la necesidad de adoptar una serie de medidas sanitarias con repercusiones de peso a nivel económicas, sociales, culturales, educativas y psicológicas a costa de preservar el derecho a la vida. En este ensayo, se rescatarán aquellas situaciones que han impactado en el campo educativo y las oportunidades que pueden darse al implementar el modelo de educación a distancia para tratar de disminuir dichas consecuencias.

Existen muchos elementos que podrían ser atendidos, pero se dará prioridad a cinco de ellos: a) la interrupción del periodo académico; b) la abrupta utilización de las tecnologías, para el desarrollo de los procesos de enseñanza y aprendizaje; c) la carencia de planificación educativa para el desarrollo de 
propuestas educativas a distancia con apoyo de tecnologías; d) la falta de recursos didácticos para utilizar en el modelo de educación a distancia; e) la necesidad de fortalecer el desarrollo de competencia tecnológicas en el personal docente.

La estructura propuesta para el desarrollo de este trabajo será la descripción de las problemáticas y breve descripción de ellas, en contraposición con aquellas oportunidades que ofrece la educación a distancia para subsanar o reducir los resultados negativos de la situación descrita.

\section{La interrupción del periodo académico}

La pandemia generó, de manera violenta, el desarrollo de una serie de medidas sanitarias con el objetivo de buscar preservar la vida de las personas. El distanciamiento social ha sido necesario para intentar evitar el aumento de contagios de manera exponencial. Sin embargo, muchas de las actividades económicas, sociales y educativas se desarrollaban sin considerar esta restricción. Por tal razón, se procedió, de forma inmediata, a la suspensión de ellas.

Así, las instituciones educativas, en todos sus niveles, se vieron obligadas a cerrar sus puertas y, con ello, la suspensión o cese de las actividades formativas y extracurriculares del estudiantado. Según Elgueta (2020), a este fenómeno se le ha denominado en muchos países de Latinoamérica "la suspensión sin suspensión".

Según el informe UNESCO/ IESALC (2020), los países de América Latina fueron de los primeros en la implementación del cierre de instituciones educativas. Muchas de ellas ya no estaban funcionando para el 12 de marzo del presente año y, a finales de ese mes, solamente las instituciones de educación superior de Estados Unidos, México y Brasil eran las únicas que se encontraban en pleno funcionamiento todavía.

Cuando se lleva a cabo la suspensión del funcionamiento de los centros e instituciones educativas, el mundo entero se enfrenta a un proceso de incertidumbre ante el desconocimiento de los embates del virus. Por ello, se entiende que, en ese momento, no se tenía considerada la magnitud del problema y, mucho menos, su duración. Hoy queda claro que se trata de un fenómeno que costará bastante tiempo contrarestarlo y, mientras no se cuente con una vacuna, el confinamiento se prolongará sin un tiempo determinado de finalización.

En relación con el tema, el informe de UNESCO/IESALC (2020) indica que, las instituciones de educación superior han enfrentado disrupciones importantes. Por tal razón, "...el impacto de esta disrupción es muy variable y depende, en primer lugar, de su capacidad para mantenerse activas en sus actividades académicas y, en segundo lugar, de su sostenibilidad financiera" (p. 6).

Entre las principales implicaciones de la interrupción del periodo académico está, en primer lugar, el retraso en el desarrollo de los programas educativos. Este aspecto preocupa, dado que no se ha logrado establecer procesos para la recuperación de ese tiempo y, sobre todo, de los contenidos y procesos de aprendizaje que dejó de tener la población estudiantil (BID, 2020).

Ante los embates económicos, en muchas instituciones de educación superior, se optó por suspender programas de asignaturas o cursos que estaban diseñados para ser desarrollados de forma presencial. Aunado al retraso en la formación del estudiantado, se dio como consecuencia adicional, el retiro de la población estudiantil o el congelamiento de matrícula y, consecuentemente, el incremento de problemas para la sostenibilidad financiera de las instituciones de educación superior, las cuales han realizado recortes en la contratación de personal docente y el desarrollo de otras actividades propias del quehacer de las universidades como son la investigación y la extensión socio-cultural (CEPAL, 2020). 
Para la población estudiantil, el retraso en su proceso formativo es una de las tantas situaciones que le ha perjudicado. Muchos de ellos contaban con becas que les cubría el alojamiento y hasta la alimentación en sus instituciones, lo cual se encuentra suspendido, razón por la cual se han regresado a sus hogares. Otros servicios con los cuales dejaron de contar son el servicio de biblioteca, el servicio médico y otros de tipo administrativo (IESALC-UNESCO, 2020).

\section{La abrupta utilización en el uso de tecnologías para el desarrollo de procesos de enseñanza y aprendizaje}

Luego de la suspensión del periodo académico, las instituciones de educación superior identifican que se requiere una medida urgente para evitar mayores consecuencias descritas en el apartado anterior. Por ello, se opta por la utilización de las tecnologías para la continuación de las actividades propias de la docencia.

Debe entenderse que, como medida de emergencia, es viable por un tiempo corto que estuviera previamente definido. Sin embargo, el contexto no permitía esa consideración y las tecnologías fueron asumidas como los medios para impartir las lecciones, que con antelación se daban en muchas instituciones de forma presencial (Pedró, 2020). Algunas de las consecuencias al adoptar esta medida fueron:

- Ausencia de cambios en la planificación curricular de los programas. Por tanto, no se evidenciaron cambios en el planemiento de la metodología y la evaluación.

- Énfasis en el uso de recursos tecnológicos orientados hacia la comunicación sincrónica, por ejemplo Zoom $^{\oplus}$, Teams ${ }^{\circledast}$, Webex ${ }^{\circledast}$, Google meet ${ }^{\circledR}$ entre otros. Estos recursos han sido utilizados para el desarrollo de clases magistrales, tal como si el estudiantado estuvieran en el aula.

- Ausencia de entornos virtuales de aprendizaje para el desarrollo de las asignaturas o cursos. Esto a falta de tiempo de la planificación curricular que implica.

- Problemas de conectividad y tenencia de recursos tecnológicos por parte del estudiantado y del cuerpo docente.

La crisis no permitió la generación de condiciones para la realización del diagnóstico de las condiciones del estudiantado y el personal docente, en cuanto a la tenencia de dispositivos tecnológicos y acceso a internet. Es así, como la experiencia ha dado como resultado que, gran cantidad de ellos no cuentan con las condiciones idóneas, por lo cual el tema de utilización de recursos tecnológicos para el desarrollo de los procesos de aprendizaje se vuelve discriminatorio y excluyente (BID, 2020).

A nivel de América Latina, solamente el $52 \%$ de los hogares cuentan con equipamiento tecnológico, sin atender acá el tema de conectividad (Pedró, 2020). A manera de ejemplo, en el caso concreto de Costa Rica, para el año 2019, se evidenciaba una amplia brecha digital. Los datos arrojados por los estudios del Instituto Nacional de Estadística y Censos (2019) indicaron que, solamente un $47 \%$ de las viviendas de todo el país poseen una computadora, un $86,3 \%$ tienen acceso a internet y la mitad de ellas $(50,6 \%)$ lo hace por medio de módem.

Si la educación es considerada como un bien público (Locatelli, 2018), además es un derecho humano, se requiere del establecimiento de las condiciones que garanticen el acceso a todas las personas. Alcántara (2020) señala que la falta de un proceso de transición hacia el modelo de educación a distancia y, el diagnóstico de la tenencia de recursos tecnológicos, lo mismo que el desarrollo de competencias para su uso, han acrecentado las desigualdades y la brecha tecnológica tanto en la población estudiantil como en el personal docente. 
Brown y Salmi (2020) identifican la importancia del apoyo de los gobiernos para con las instituciones educativas. En ese sentido, se necesita como una medida de carácter urgente, el desarrollo de proyectos e iniciativas orientadas a la creación de capacidades para el aprendizaje en línea.

\section{La carencia de planificación educativa para el desarrollo de propuestas educativas a distancia con apoyo de tecnologías}

La solución viable para no suspender los procesos académicos implicó recurrir al uso de los medios tecnológicos para el desarrollo de los programas educativos (Crawford, et al., 2020). En algunas de las instituciones de educación superior, se visualizó que ello implicaba un ajuste de su modelo educativo, para pasar de lo presencial al modelo de educación a distancia. Sobre la adopción del modelo de educación a distancia, Pedró (2020) menciona que:

Universalmente, el paso a la educación a distancia, lejos de ser una solución planificada previamente y para la que existían las capacidades requeridas en los distintos actores y en el conjunto de los sistemas, ha sido, en realidad, la única solución de emergencia para intentar garantizar la continuidad pedagógica. Por esta razón, es frecuente referirse a esta continuidad pedagógica como educación a distancia de emergencia, contraponiéndola así a las capacidades y recursos que habría exigido una educación superior a distancia óptima (p. 3).

Sin embargo, tal como lo señala Rojas (2020), la transición es un proceso complejo que debe ser evaluado. En este particular, no basta con recurrir al uso de las tecnologías para asumir que se está trabajando bajo la modalidad de educación a distancia. Rojas (2020) indica que, "la implementación de la educación a distancia como respuesta a la cuarentena, plantea retos relativos a las competencias del personal docente para la adecuación de los diseños y metodologías de los cursos, así como aquellos derivados de la brecha digital de acceso a las tecnologías" (p. 3). Por tanto, la tarea no es sencilla y su ejecución podría ser difícil de realizarse a corto plazo.

Se evidencia que existe un conjunto amplio de aspectos a considerar para la planificación de propuestas educativas con apoyo de recursos tecnológicos y que se orienten desde el modelo de educación a distancia. En primera instancia, se ubica el tema de la tenencia de recursos tecnológicos y el acceso a internet para la población estudiantil y el personal docente. Los estudios demuestran que la situación es poco alentadora a nivel latinoamericano (Pedró, 2020), por lo que se corre el riesgo de generar menos oportunidades y acceso a la educación, con lo cual se aumentaría la brecha digital y, la desigualdad, en una sociedad mundial que se encuentra con una economía en crisis, donde lo que se espera es la reactivación económica, así como el desarrollo de acciones que favorezcan modelos de equidad (Alcántara, 2020).

Por otra parte, desde la teoría de educación a distancia, el uso de herramientas tecnológicas consiste solamente un medio a considerar en el proceso de aprendizaje del estudiantado. Desde este modelo, el rol de docente tiene variantes significativas con respecto a aquel que desempeña desde la presencialidad. En este caso, se convierte en un facilitador de los procesos de aprendizaje, para lo cual, se trabaja fuertemente en la mediación pedagógica de los contenidos.

Para Zabalza (2003), al incorporar las tecnologías en los procesos educativos, se requiere de contar previamente con el un replanteamiento del rol docente. Según el autor, este rol bajo las consecuencias indicadas, obliga a "... redefinir nuestro papel como docentes para centrarlo más en ayudar/orientar al alumno a navegar en el inmenso oceáno de información disponible, enseñándole a buscar lo más pertinente, orientando su búsqueda y aportando criterios para la selección" (p. 94). 
Sobre el tema, Duart y Sangrá (2000) indican que se necesita que el cuerpo docente, cuando trabaja en modelos de educación a distancia, propicie el aprendizaje utilizando recursos tecnológicos, para ello, debe considerar que la metodolgía debe ser abierta y flexible. De esta forma, se propia una educación con estándares de calidad, puesto que toma en cuenta las necesidades de la población estudiantil y, a la vez, favorece el aprender a aprender, como consigna de la educación. Duart y Sangrá (2000) amplían el tema de la metodología en modelos no presenciales e indican que:

Hay diferentes fórmulas de enseñanza no presencial, pero invariablemente estudiar a distancia implica esfuerzo y constancia. Es necesario, pues, una metodología que lo facilite, una metodología adaptada a las necesiddes crecientes y cambiantes de unos sectores sociales que quieren acceder a la unviersidad y que presetan unas características muy diferentes de edad,lugar de residencia y situación personal (p. 28).

Otro elemento por analizar, es el hecho de que la educación presencial ha puesto un énfasis en el contenido y propiamente en su transmisión, lo cual debería variar desde la educación a distancia. Acorde con el tema, Crespo y Palguachi (2020) consideran que se requiere de un replanteamiento total del modelo educativo, desde el cual se brinde mayor atención a las actividades de mediación que a los contenidos. En ese sentido, Chehaibar (2020) apunta hacia la estructuración de propuestas educativas que consideren, de forma explícita, mayores elementos orientados al desarrollo de la flexiblidad curricular en la oferta.

Aunado a lo anterior, debe tener en cuenta que la población estudiantil debe tener un rol diferente al que normalmene se le asigna en la educación presencial. Desde esta perspectiva, su rol es protagónico donde, además de su activa participación en su proceso formativo, debe fortalecer las competencias como, la planificación, el trabajo en equipo, uso de tecnologías, manejo de la frustración y resolución de conflictos.

Rojas (2020), en relación con el tema, señala que, en la educación a distancia, hay más elementos a considerar que el uso de las tecnologías. Por ello, opina que el aprendizaje lo lleva a cabo el estudiantado en solitario, dado que "... aprendizaje individual se fortalece por medio del aprendizaje colectivo, para lo cual la institución educativa y sus profesores deben facilitar una comunidad de aprendizaje que genera colaboración entre los y las estudiantes" ( $\mathrm{p}$ 3). Por lo tanto, la población estudiantil participa en procesos donde es co-constructora de un ambiente de aprendizaje interactivo que, es facilitado por el uso de las tecnologías. Al respecto, Berrocal (2017) indica que se requiere de su mentalidad abierta para que pueda compartir diversas experiencias con sus pares y el equipo docente.

\section{La falta de recursos didácticos para utilizar en el modelo a distancia}

Entre los sustentos teóricos de la educación a distancia, es indispensable contar con recursos didácticos mediados pedagógicamente. El recurso didáctico que se encuentra mediado pedagógicamente, es aquel que tiene acceso al estudiantado y que, le sirve como guía y orientación para el proceso formativo (UNED, 2014). Podría decirse metafóricamente que, este tipo de material sería como tener a la persona docente en el aula presencial, por lo tanto en modelos de educación a distancia es fundamental su desarrollo e implementación contando con las características mencionadas.

Para lograr contar con materiales de este nivel, es necesario el desarrollo previo de un amplio proceso de planificación curricular que, inicia desde el plan de estudios del programa académico, donde se brindan orientaciones generales de metodología, evaluación y objetivos y componentes de cada una de las asignaturas o cursos que serán ofertados (Umaña, 2017). En un segundo momento, se debe contar con un diseño didáctico de cada asignatura o curso, donde detalles de los recursos didácticos y los medios tecnológicos a utilizar en una asigntura, en función de los objetivos de aprendizaje propuesto. Finalmente, 
en una tercera fase, se inicia el proceso de producción del material, donde se parte de la premisa de contar con un equipo interdisciplinario de especialistas para culminar de forma exitosa la tarea.

Duart y Sangrá (2000) señalan que, en los modelos a distancia apoyados por el uso de tecnologías, generalmente se trabaja en entornos virtuales de aprendizaje, mediante el acceso a diferentes plataformas. En este contexto, el libro de texto tradicional pierde sentido; por ello, estos autores insisten en que:

Los entornos virtuales de aprendizaje los materiales didácticos acostumbran a ser multimedia, es decir, combinan diferentes tecnologías al alcance (textos, registros, videos) desde una perspectiva de máximo provecho pedagógico. Son una guía básica en el desarrollo de cada asignatura. Sobre ellos se desarrollará la acción docente y la evaluación (Duart y Sangrá (2000, p. 36).

Ante la emergencia suscitada por la pandemia, es lógico que los recursos didácticos no contaran con las características básicas, pero esenciales para poder ser utilizados en modelos educativos a distancia. Además, los problemas económicos que están experimentando las instituciones educativas les ha limitado la contaratación de persona académico con experiencia, lo mismo que diseñadores instruccionales que, pudieran orientar de la mejor manera, los cambios en forma y fondo de los recursos didácticos (Alcántara, 2020). Esta problemática, puede generar vacíos en la formación del esudiantado y el cumplimiento parcial de objetivos de aprendizaje.

\section{La necesidad de fortalecer el desarrollo de competencias tecnológicas en el personal docente}

Tal y como lo señalan Salas y Umaña (2017), la docencia, en un modelo de educación a distancia, “... implica una gran responsabilidad y más aún con la integración de propuestas de e-learning, porque la cantidad y variedad de recursos tecnológicos de que se dispone es cada día mayor" (p. 53). Significa que, no basta con tener un título de licenciatura en docencia o áreas afines, sino que implica una sólida formación orientada hacia la pedagogía de la educación a distancia.

En el momento en que se toma la decisión de implementar sus lecciones bajo la modalidad a distancia por la crisis actual, es imposible llevar a cabo, en tan corto tiempo, un proceso de formación para la comprensión del modelo por parte del personal docente, lo mismo que la realización de una preparación de calidad (Brown y Salim, 2020). Tampoco se podía desarrollar en cuestión de unas cuantas semanas, la formación en el uso de recursos y herramientas tecnológicas para fines educativos, tal cual debería ser.

A la fecha, tal como lo refiere Elgueta (2020), mucho del personal docente, a nivel latinoamericano, se ha enfrentado a los problemas de conectividad y tenencia de equipo. Pues, en muchos hogares, se contaba con una computadora, la cual debe ser compartida por diversos miembros de la familia.

Además, el equipo docente debe hacer esta abrupta incursión al modelo de educación a distancia del cual tiene poco conocimiento y, le demandaría un amplio y riguroso proceso de aprendizaje, lo cual puede generar mucha frustración en el personal docente. Pedró (2020), en relación con el tema, menciona que:

Esta entrada abrupta en una modalidad docente compleja, con múltiples opciones tecnológicas y pedagógicas, y con una curva de aprendizaje pronunciada, puede saldarse con resultados poco óptimos, frustración y agobio debido a la adaptación a una modalidad educativa nunca antes experimentada sin la correspondiente capacitación para ello (p. 6). 
En relación con el tema, Barrón (2020) señala que, en primera instancia, es necesario repensar la educación y los roles que tiene el estudiantado y el personal docente. Esta tarea, según la autora, es fundamental para replantear la educación en todas sus dimensiones. Sugiere que el aprendizaje en línea no está conceptualizado para sobresaturar los medios tecnológicos con funciones pedagógicas, lo cual ha ocurrido en esta época y es fiel reflejo de las falencias en desarrollo de competencias por parte del cuerpo docente.

En su informe sobre los efectos de la crisis en educación, producto del virus responsable de la COVID-19, la Organización de Estados Iberoamericanos para la Educación, la Ciencia y la Cultura (2020) indica que la tarea que queda por hacer es la capacitación del personal docente, para la adecuada implementación del modelo de educación a distancia en los diversos niveles del sistema educativo. Sin embargo, esta tarea que, está en pendiente hasta el día de hoy.

\section{Oportunidades del modelo de educación a distancia posterior al Coronavirus}

El modelo de educación a distancia, por su filosofía cuenta con un cúmulo de principios a nivel epistemológico, metodológico y evaluativo que, le hacen ser la alternativa viable para su implementación en tiempos del Coronavirus y posterior a la erradicación del virus.

Estas oportunidades merecen un análisis detallado, según el contexto en el cual, se desea implementar. En el fondo, lo que se persigue es evitar la generación masiva del modelo, lo cual podría traer consigo resultados negativos a corto plazo, más de los que ya han sido mencionados en este escrito. A continuación, se describen brevemente, algunos de esas características que han posicionado a la educación a distancia como la alternativa para el desarrollo de modelos educativos.

Según autores como Simonson, Smaldino, Albright y Zvacek (2006), la educación a distancia se caracteriza por:

- Separación física entre el estudiantado y el personal docente.

- Existen diversos medios de comunicación (escrita, impresa u otra) para la realización del proceso educativo.

- $\quad$ El proceso de enseñanza es individualizado.

- El proceso de aprendizaje lo lleva a cabo el estudiantado, a partir de actividades que hace por cuenta propia.

- El estudiantado tiene un rol activo en su proceso formativo. De hecho, tiene en sus manos la responsabilidad de definir el estilo de planificación y ritmo de las actividades académicas.

Los aspectos mencionados son realmente fundamentales para el desarrollo de procesos formativos, en donde no es necesario el traslado físico y, donde las condiciones particulares de cada persona estudiante pueden ser atendida de forma integral, sin que se vean entrabados sus estudios. Ante el panorama actual de distanciamiento social, todos los elementos indicados son, en sí, las condiciones que han llevado a tomarla como opción actual.

Por otra parte, los modelos de educación a distancia se han caracterizado por sus procesos de planificación previa en todos los niveles. De esta manera, se logra garantizar la oferta de calidad, según los estándares establecidos previamente en los planes de estudio. Las experiencias actuales demandan este tipo de planificación, pues tal como ya se ha descrito, los esfuerzos solamente han generado sostenibilidad 
de las ofertas educativas, no así su efectividad y logro. Desde la educación a distancia, hay una garantía para este proceso y también es un requisito como tal para su desarrollo.

A nivel metodológico, desde la educación a distancia se busca que se promueva la participación del estudiantado. En este caso, la figura de la persona docente pasa a tener un rol de facilitador del aprendizaje. De esta manera, la metodología no se centra en la transmisión de contenido, sino en las estrategias para el desarrollo del aprendizaje de la población estudiantil. Cuando se hace uso de tecnología, Duart \& Sangrá (2000) refieren que "...la acción docente en el contexto de la virtualidad hace necesario centrar la atención del estudiante en la actuación del profesor, sino potenciar la actividad del estudiante según su proceso de aprendizaje" (p. 38).

Las condiciones expuestas sobre las acciones y funciones de quien ejerce la docencia son realmente ventajosas en un contexto como el actual, donde se encuentran procesos fuertes de desigualdad no solo en recursos tecnológicos, sino en conocimiento, situaciones personales entre otras. Desde la educación a distancia, se debe orientar el proceso hacia el aprendizaje y no hacia la enseñanza.

En lo que respecta al campo de la evaluación de los aprendizajes, la educación a distancia, al igual que la educación presencial ha estado fuertemente influenciada por modelos tradicionales de evaluación, orientados a medir $y$, donde las pruebas escritas han sido consideradas como el instrumento principal a utilizar (Rodríguez \& Ibarra, 2011). Sin embargo, con la incorporación de las tecnologías como medios de apoyo en los procesos educativos, se hace necesario un replanteamiento sobre los fines de la evaluación.

Rodríguez e Ibarra (2011) consideran que la evaluación debe estar orientada hacia el aprendizaje, por lo tanto, debe:

Partir de una concepción abierta, flexible y compartida del conocimiento, centrando la atención en el uso de estrategias de evaluación que promueven y maximizan las oportunidades de aprendizaje de la población estudiantil, en contra posición a la certificación o validación de estos a través de la evaluación sumativa. (p. 35)

Este replanteamiento en la evaluación permite, al equipo docente, el uso de una serie de recursos y herramientas tecnológicas para su desarrollo. También, facilita espacios evaluativos compartidos, donde la población estudiantil tiene papeles protagónicos para evaluar su propio proceso de aprendizaje, así como el de sus compañeros (Rodríguez e lbarra, 2011).

La educación a distancia como tal, ha evolucionado en relación con el tipo de medios y recursos para apoyar los procesos de aprendizaje. Algunos modelos cuentan con experiencias en las cuales hay espacios presenciales pero se limitan a actividades como orientar, apoyar y brindar explicaciones y aclaraciones al estudiantado por parte del personal docente; muchos modelos llaman a estos espacios tutorías. En la época de la pandemia, las migraciones a la virtualidad total fueron la característica de las instituciones que se desarrollan bajo este modelo. Al respecto, la tarea no fue tan compleja, dado que en general cuentan con sus plataformas de aprendizaje para la experticia del equipo docente y del estudiantado en su uso. Este tipo de modelo ha realizado los ajustes y ha funcionado con la misma normalidad, solamente que totalmente virtual. Esto ha llevado a la potenciación del uso de recursos y herramientas, aplicaciones tecnológicas y experiencias enmarcadas en marcos pedagógicos que las sustentan. De esta forma, se tiene ya conocimiento de los aciertos y desaciertos en estos procesos, lo cual es beneficioso para la búsqueda de mejoras a corto plazo.

Finalmente, hay que destacar que, en la educación a distancia, se cuenta con equipos humanos que, desde sus diferentes funciones, son partícipes en el desarrollo de la docencia. Estos equipos cuentan con el personal docente especialistas en contenido, productores académicos con amplia experiencia en el desarrollo y la implementación de tecnologías para procesos educativos, expertos en mediación 
pedagógica, informáticos entre otros. De esta manera, se contabiliza una sólida estructura para la gestión de los procesos educativos que, ante eventos de crisis, pueden hacer ajustes rápidamente sin causar afectaciones mayores a la población estudiantil, ni al cuerpo docente.

A manera de síntesis, sobre las oportunidades en la incorporación del modelo educativo a distancia y de aprendizaje en línea, se destacan las siguientes:

a) El desarrollo de habilidades y competencias en la población estudiantil, que serán de gran utilidad en su desenvolvimiento profesional.

b) La ruptura con el rol y las funciones tradicionales del docente, lo cual trae consigo un replanteamiento en la formación de formadores y sus posibles habilidades para "aprender a lo largo de la vida" como uno de los pilares fundamentales.

c) Uso de recursos tecnológicos y recursos didácticos creados en atención de las poblaciones estudiantiles.

d) El acceso a la educación para las personas como un derecho humano al cual tienen acceso.

\section{Retos del modelo de educación a distancia posterior a la pandemia}

Los modelos de educación a distancia tienen retos importantes que enfrentar, posterior a la época de la enfermedad del Coronavirus. En primeras instancias, las bondades de este modelo para su implementación y adopción en instituciones que lo quieran asumir implican una fuerte inversión en recursos financieros, tecnológicos y humanos. En ese sentido, les corresponde, a los expertos, generar las redes de apoyo y colaboración para la orientación y adecuada incursión en esta modalidad educativa. El reto en este caso es, el establecimiento de estrategias y actividades de cooperación nacional e internacional entre instituciones de educación superior. Sobre este particular, Alcántara (2020) indica que, a la fecha, al no haberse dado el proceso de transición de la presencialidad hacia modelos educativos a distancia, implica considerar entre otros factores: la búsqueda de sistemas efectivos para la gestión de los aprendizajes según las necesidades de la institución educativa y el contexto social, la instalación de sistemas de videoconferencias que cuenten con las garantías para el desarrollo de sesiones sincrónicas y, finalmente, contar con el personal académico con experiencia en el desarrollo de modelos de educación a distancia y aprendizaje en línea.

Otro de los retos que se tiene desde este modelo, es la búsqueda de estrategias para contribuir en la recuperación económica y social de los países (IESALC-UNESCO, 2020). Al respecto, se requiere de la revisión de la oferta educativa de las universidades, dado que, con la crisis, hay profesiones que están siendo replanteadas, y otras parecieran ser ya del pasado. Ligado a lo anterior, es necesario hacer un análisis de las demandas sociales del contexto para valorar las áreas en que se deben expandir las ofertas de formación profesional.

La pandemia ha dejado al descubierto la necesidad de que las personas desarrollen una serie de conocimientos y competencias que, ante una eventual crisis, puedan continuar con sus procesos productivos; en este sentido, desafíos importantes a subsanar. El primero de ellos consiste en la generación de programas de actualización profesional para los graduados, de manera que puedan estar "reinventando" su profesión acorde con el medio sociocultural en el que se desenvuelven.

Finalmente, en la misma línea que se viene planteando, se necesita del desarrollo de cursos, programas y proyectos bajo la modalidad a distancia abiertos al público en general. De esta manera, se pueden generar ofertas de técnicos, alfabetización digital, emprendedurísmo, entre otros. Sin embargo, para 
llegar a este punto, es necesario hacer evaluaciones del impacto que se ha tenido en la implementación, de manera que se consideren los logros y necesidades por solventar (Crawford et al., 2020).

\section{SÍNTESIS Y REFLEXIONES FINALES}

Tal como se indicó en páginas anteriores, la existencia de educación a distancia no es reciente, su historia es bastante antigua y los logros de esta modalidad tienen sus registros de larga data. Entre las principales oportunidades de la educación a distancia que han sido ratificadas en en la época de la pandemia, están las opciones que se brindan para el acceso a la educación con recursos alternativos, para que ni el personal docente, ni el estudiantado se vean expuestos a riesgos potenciales por la pandemia. Además, de esta manera, se logra en alguna medida, mantener el curso lectivo. Pero más que eso, también se potencia la alternativa de un modelo educativo que no requiere del desplazamiento físico ni la coordinación temporal entre las personas docentes y el estudiantado. Así las cosas, es evidente que la educación a distancia y el aprendizaje en línea, están abriendo nuevos espacios educativos para que más personas puedan continuar su formación a nivel superior.

En esta misma línea de pensamiento, cualquier institución con un modelo a distancia, tiene mayores posibilidades de expandir su oferta académica tanto a nivel del país, como de la región y a nivel internacional.

Puede incluirse en esta lista de oportunidades, las posibilidades de contar con ofertas interculturales, dado que se puede contar con personal docente invitado y estudiantado de otros países, sin que sea necesario su traslado de su país de residencia, lo cual enriquece a todas las personas participantes por el intercambio de experiencias y vivencias; esto crea espacios propicios para la construcción de nuevos conocimientos. Por lo tanto, se abre una nueva alternativa para el desarrollo de movilidad virtual para el equipo docente y la población estudiantil, de menores costos y con una serie de beneficios para los involucrados, lo mismo que para las instituciones a las que pertenecen.

Entre los principales retos de la educación a distancia, está el desarrollo de programas de educación continua para el fortalecimiento de las competencias digitales del cuerpo docente. Esta tarea debe verse en un ritmo flexible, variable y tan cambiante como lo demande el contexto social, y sus avances en el desarrollo tecnológico.

Otro de los retos, consiste en buscar la creación de politicas universitarias que puedan favorecer el acceso a la modalidad educativa de la población estudiantil. Para ello, se requiere de una infraestructura tecnológica y física que sea puesta a disposición del estudiantado. Aunado a este tema, es necesario contar con el apoyo de los gobiernos, pues hay temas de conectividad y acceso a recursos que no dependen exclusivamente de las instituciones educativas. En estos tiempos, los aprendizajes orientan a pensar en el desarrollo de alianzas y colaboraciones entre las instituciones educativas, el gobierno y el sector privado, como una de las estrategias para el rescate social y económico en Latinoamérica.

También, es necesario el diagnóstico del estudiantado, donde se tomen en cuenta no solo sus caractarísticas demográficas, sino un posible perfil tecnológico que remita a la identificación de sus condiciones de acceso a recursos tecnológicos y de conectividad, tema que, en la pandemia, ha sido uno de los grandes problemas $y$, que no puede ser solventado por las instituciones educativas, sino que depende de decisiones del gobierno. Aún así, se podría colaborar con el suministro de datos e información que oriente a los estados, en la priorización de zonas para dotar de este acceso a su población y no limitar sus posibilidades de estudio. 
Ante la emergencia que se vive, es comprensible los procesos educativos desarrollados de manera inexperta e improvisada. Sin embargo, es indispensable pensar, desde ya, en proyectos de investigación que permitan determinar el impacto de este tipo de prácticas en el proceso formativo de las personas.

Se requiere generar espacios para compartir las prácticas educativas implementadas, de manera que la comunidad docente, pueda ir fortaleciendo su conocimiento en el manejo del modelo a distancia y, de los recursos tecnológicos. En ese sentido, sería pertinente identificar cuales medios y recursos tecnológicos utilizan, lo mismo que las herramientas o aplicaciones que son usadas para la mediación pedagógica. Esto por cuanto hay muchas aplicaciones que cumplen alguna función educativa aunque no fueron creadas para ello, tal como es el caso del Facebook ${ }^{\circledR}$ o el Whatapps ${ }^{\circledR}$.

No cabe duda de que, la educación a distancia y el aprendizaje en línea se convierten en una de las opciones con mayores posibilidades para continuar siendo asumidas por las instituciones educativas. Sin embargo, la implementación real de este modelo demanda cambios radicales en las filosofías de los centros de enseñanza, por lo tanto, uso de virtualidad no es sinónimo de educación a distancia. En esta línea, es importante conocer si realmente las personas en ejercicio de la docencia están convencidas de ello, pues lo primero es el cambio cognitivo para creer en el modelo educativo como una opción tan válida y real como cualquier otra. Si el personal docente no lo tiene claro, transmitirá, al estudiantado, los temores e incredulidad por este tipo de modalidad, con lo cual se trunca todo proceso de aprendizaje real.

Sin dejar de lado lo expuesto, tampoco se trata solo de una transforamción en la planificación curricular meramente, sino que conlleva cambios importantes en la gestión y la conceptualización de lo que es enseñar y aprender. Trascender a modelos orientados desde la educación a distancia permite la reactivación de proyectos formativos acordes con las nuevas necesidades del contexto, posterior a la pandemia.

\section{REFERENCIAS}

Alcántara, A. (2020). Educación superior y covid-19: una perspectiva comparada. En: Educación y pandemia. Una visión académica. México. Recuperado en http//www.iisue.unam.mx/nosotros/covid/ educacion-y-pandemia.

Banco Interamericano de Desarrollo (BID). (2020). La educación superior en tiempos de COVID-19. Aportes de la segunda reunión del diálogo virtual con rectores de universidades líderes en América Latina. Recuperado de http://dx.doi.org/10.18235/0002481

Barrón, M. (2020). La educación en línea. Transiciones y disrupciones. En: Educación y pandemia. Una visión académica. México. Recuperado en http//www.iisue.unam.mx/nosotros/covid/ educacion-y-pandemia

Berrocal, V. (2017). El estudiantado en entornos virtuales de aprendizaje. En: Umaña, A; Salas, I.; Berrocal, V. Consideraciones para el diseño y oferta de asignaturas en línea. Universidad Estatal a Distancia, San José, Costa Rica.

Brown, C.; Salmi, J. (2020). Putting fairness at the heart of higher education. UniversityWolrd News. Global window on higher education. Recuperado de universityworldnews.com/post. php?story $=20200417094523729$

Chehaibar, L. (2020). Flexibilidad curricular. Tensiones en tiempos de pandemia. En: Educación y pandemia. Una visión académica. México. Recuperado en http//www.iisue.unam.mx/nosotros/covid/ educacion-y-pandemia.

Comisión Económica para América Latina y el Caribe (CEPAL). (2020). Dimensionar los efectos del covid-19 para pensar en la reactivación. Recuperado de: https://www.cepal.org/es/ publicaciones/45445-dimensionar-efectos-covid-19-pensar-la-reactivacion 
Crawford, J. Butler-Henderson, K.; Malkawi, B.;Lam, S.; Rudolph, J.;Mangi, P.; Glowatz, M. (2020). COVID-19: 20 countries higher educational intra-perior digital pedagogy responses. En: Journal of applied learning \& teaching. Recuperado de http://jourals.sfu.ca/jalt/index.php/jalt/index

Crespo, M.; Palaguachi, M. (2020). Educación con tecnología en una pandemia: breve análisis. En: Revista Scientific 5(17), p.292-310. Recuperado de https://doi.org/10.29394/Scientific. isnn.2542.2987.2020.5.17.16.292-310

Duart, J.; Sangrá, A. (2000). Aprender en la virtualidad. España: Gedisa editorial.

Elgueta, M. (2020). Desafíos de la educación jurídica latinoamericana en tiempos de pandemia. En: Revista pedagógica universitaria y didáctica del derecho, vol 7 (1). Chile.

Instituto nacional de estadística y censo. (2019). Informe sobre microempresas de los hogares por sector de actividad económica según año y tecnologías de información y comunicación utilizadas. San José, Costa Rica.

Locatelli, R. (2018). La educación como un bien público y común. Reformular la gobernanza de la educación en un contexto cambiante. En: Perfiles educativos, vol 40,no. 162. México.

López, M.; Rodríguez, S. (2020). Trayectorias escolares en la educación superior ante la pandemia: ¿continuar, interrumpir o desistir? En: Educación y pandemia. Una visión académica. México. Recuperado en: http//www.iisue.unam.mx/nosotros/covid/educacion-y-pandemia.

Organización de Estados Iberoamericanos para la Educación, la Ciencia y la Cultura (OEI). (2020). Efectos de la crisis del coronavirus en la educción. Madrid, España

Ordorika, I. (2020). Pandemia y educación superior. En: Revista de educación superior, vol 49. Recuperado de: https//doi.org/10.36857/resu.2020.194.1120

Pedró, F. (2020). Covid-19 y educación superior en América Latina y el caribe: efectos, impactos y recomendaciones políticas. Recuperado de: https://www.fundacioncarolina.es/wp-content/ uploads/2020/06/AC-36.-2020.pdf

Rodríguez, G.; Ibarra, M. (2010). e-Evaluación orientada al e-aprendizaje estratégico en educación superior. España: Narcea.

Rojas, R. (2020). Informe de avance. Efectos de las medidas tomadas en el país y en la UNED a raíz de la pandemia sobre los procesos de aprendizaje de la persona estudiante, así como su contexto familiar y personal. San José, Costa Rica: UNED.

Salas, I.; Umaña, A. (2017). Importancia de la figura del profesor. En: Umaña, A; Salas, I.; Berrocal, V. Consideraciones para el diseño y oferta de asignaturas en línea. Universidad Estatal a Distancia, San José, Costa Rica.

Seow,B.(2020,enero, 22). OMS evalúa declarar «emergencia de salud pública a nivel internacional» por coronavirus. Semanario Universidad. Recuperado de: https://semanariouniversidad.com/mundo/ oms-evalua-declarar-emergencia-de-salud-publica-a-nivel-internacional-por-coronavirus

Simonson,M.; Smaldino, S., Albright, M.; Zvacek, S. (2006). Teaching and learning at distance: Foundations of distance education. (3 ed.). New Jersey: Pearson.

IESALC-UNESCO.(2020). Covid-19 y educación superior: de los efectos inmediatos al día después. Análisis de impactos, respuestas politicas y recomendaciones. Recuperado de: http://www.iesalc. unesco.org/wp-content/uploads/2020/05/COVID-19-ES-130520.pdf

Umaña, A. (2017). La planificación curricular y el diseño curricula de asignaturas en línea. En: Umaña, A; Salas, I.; Berrocal, V. Consideraciones para el diseño y oferta de asignaturas en línea. Universidad Estatal a Distancia, San José, Costa Rica.

Zabalza, M. (2003). Competencias del profesorado universitario. Calidad y desarrollo profesional. España: Ediciones Narcea, S.A. 